\title{
Coaptation and functional bracing of adolescent humeral shaft spiral fracture: a case report and review of literature
}

\author{
Thiyagarajan Thiagarajan Singaram*, Giriraj Harshavardhan J. K.
}

\begin{abstract}
Department of Orthopaedics, Sri Ramachandra Institute of Higher Education and Research, Porur, Chennai, Tamil Nadu, India
\end{abstract}

Received: 11 February 2020

Accepted: 27 February 2020

\section{*Correspondence:}

Dr. Thiyagarajan Thiagarajan Singaram,

E-mail: drtsthiyagarajan@gmail.com

Copyright: (C) the author(s), publisher and licensee Medip Academy. This is an open-access article distributed under the terms of the Creative Commons Attribution Non-Commercial License, which permits unrestricted non-commercial use, distribution, and reproduction in any medium, provided the original work is properly cited.

\begin{abstract}
Adolescent humerus shaft fractures are uncommon. Direct injuries lead to transverse fractures and indirect injuries lead to spiral and most oblique fractures. There is fracture displacement, angulation and internal rotation of the proximal fragment. There is difficulty in maintaining reduction after closed manipulation of spiral fractures. Paediatric humeral shaft fractures are treated by elastic intramedullary nails more often nowadays. We present a case of isolated spiral fracture of the middle1/3rd and distal $1 / 3$ rd junction of the humerus shaft with displacement and angulation treated successfully with closed reduction, coaptation $U$ slab followed by functional orthosis.
\end{abstract}

Keywords: Paediatric, Humeral shaft, Spiral fracture, Closed reduction, Functional bracing

\section{INTRODUCTION}

Paediatric humeral shaft fractures are an uncommon entity. It represents $5 \%$ or less of paediatric fractures and $20 \%$ or less of all humeral fractures in children. ${ }^{1}$ The injury has a bimodal distribution in the paediatric age group-below 3 years and adolescents. The mechanism of injury and therefore the treatment of both groups are significantly different. Spiral fractures are low to moderate velocity twisting injuries and have a lot of deforming muscle forces. We would like to report a case of a humeral shaft spiral fracture in an adolescent treated conservatively utilizing a coaptation splint and functional bracing.

\section{CASE REPORT}

A 13 years old healthy boy sustained closed injury to the left arm due to fall from a tree on outstretched hand. He had pain and difficulty moving the left upper limb post fall and presented to us the next day with a sling. He had no comorbidities. On examination, he was found to have swelling and deformity in the middle third of the left arm and external abrasions in the distal third of the arm. Distal pulses were intact. The sensations were intact over the arm segment. Motor and sensory function of the radial, ulnar and median nerves were intact.

Plain radiography of the left humerus showed a spiral fracture of the humeral shaft with lateral displacement of $1 \mathrm{~cm}$, varus tilt of $10^{\circ}$, anterior angulation of $20^{\circ}$ and internal rotation of the proximal fragment. The patient was initially advised surgery at another hospital before he presented to us (Figure 1a and b).

The child was taken up for elective closed reduction the next day. Under adequate anaesthesia and muscle relaxation, manipulation and closed reduction under image intensifier guidance was done. Displacement was reduced but varus tilt of $10^{\circ}$ was persistent in the coronal plane. The posterior tilt was reduced to $10^{\circ}$. Since acceptable radiological parameters were present, Coaptation U slab was applied (Figure 1c). 
Post recovery from anaesthesia, radial nerve motor and sensations were tested and found to be normal. The child was maintained on U-slab with sling and returned to scholastic and routine activities with guarded left hand movements.
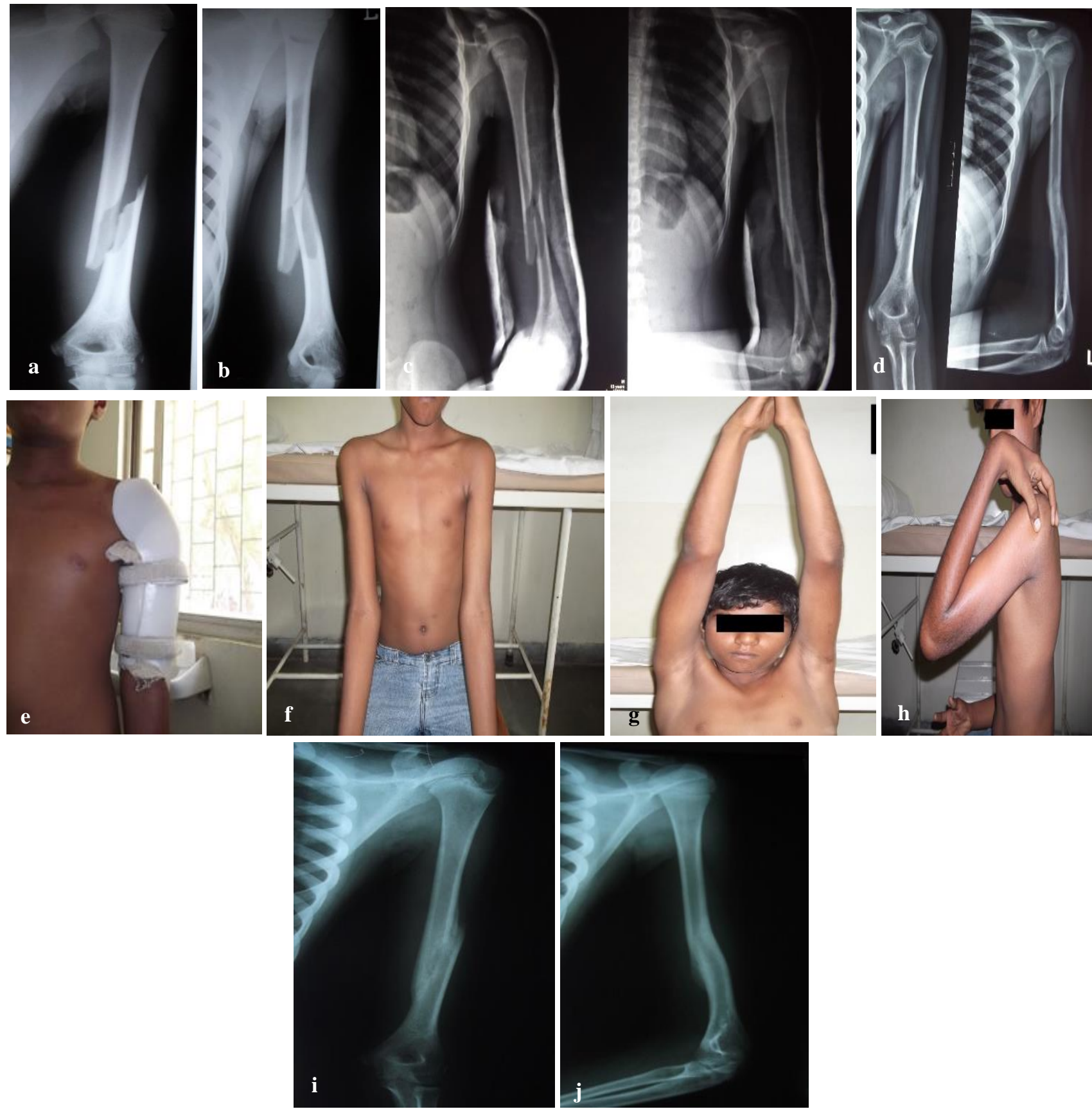

Figure 1: (a) AP X-ray of shaft of humerus spiral fracture, (b) lateral X-ray of humerus shaft spiral fracture, (c) post-coaptation U-slab application, (d) 4-week follow-up post U-slab removal, (e) custom made functional orthosis applied, (f) clinical picture post complete healing, no visible deformity noted, (g) shoulder range of movements post complete healing, (h) full elbow movements post complete healing, (i) complete healing at 3 months follow-up AP X-ray and (j) complete healing at 3 months follow-up lateral X-ray.

The child was followed up weekly for the first two weeks and serial X-rays did not show any loss of reduction achieved. The child was followed up and the slab was removed in 4 weeks and radiographs repeated. Radiographs showed callus at the end of the spiral fracture site. Abnormal mobility was absent but complete radiological healing could not be documented. The range of movements of the elbow was full and terminally restricted for the left shoulder. Custom made thermoplastic functional humerus orthosis was made and applied. He was allowed to mobilize his left elbow and left shoulder with the orthosis. The child was followed up monthly with serial X-rays (Figure 1d and e). 
At the end of 3 months, complete radiological healing was achieved. The range of movements of the elbow was full and free. The range of movements of the shoulder was near normal. No deformity was noted clinically (Figure 1f-h).

X-ray showed $7^{\circ}$ of anterior angulation and $7^{\circ}$ of varus tilt. The length of the arm segment was reduced by $1 \mathrm{~cm} .10^{\circ}$ of rotational malalignment noted. All parameters were within acceptable limits with near normal function. Child is currently 15 years of age and doing all routine activity and also strenuous and sporting activities with the affected hand (Figure $1 \mathrm{i}$ and $\mathrm{j}$ ).

\section{DISCUSSION}

Humeral shaft fractures in the adolescent age group are rare. They are more prone for proximal and distal humeral fractures. Most common injury is a transverse or short oblique fracture due to direct trauma. Spiral fractures are indirect moderate velocity injuries with fall on the outstretched hand. All these fractures tend to heal uneventfully. ${ }^{2}$

Radial nerve is rarely injured. ${ }^{3}$ If injured either during initial injury or during manipulation, it will mostly recover in a short duration. Very rarely will open decompression be required. Most of these injuries are compression and stretch injuries to the nerve and very rarely transection and entrapment, probably due to few muscle fibres separating the bone and the nerve.

Humeral shaft transverse fractures may be associated with extensive soft tissue injury with or without open wounds. Spiral and most oblique fractures are rarely open injuries, due to the indirect nature of the insult. Multiple injuries are common in shaft of humerus injuries. ${ }^{4}$ Either polytrauma or polyskeletal injuries are present in a large proportion of cases. Floating elbow injuries with forearm fractures are also noted.

Displacement of the fracture is based mainly on the attachment of the deltoid muscle for transverse fractures, the position in which the arm is held and also the forces causing the fracture. ${ }^{1}$ Spiral or oblique fractures are posteriorly displaced or tilted and medially or laterally tilted or displaced.

Most of isolated humeral shaft fractures are treated conservatively worldwide. ${ }^{5}$ Surgical stabilization of shaft fractures is required in polytrauma and open injuries. Older papers give acceptable angulation of $25-30^{\circ}$ in the proximal shaft, $20^{\circ}$ in the midshaft and $15^{\circ}$ in the lower shaft for conservative treatment. ${ }^{3}$ Greater degree of deformity tends to have cosmetic deformity but no functional limitation. Newer recommend limits of maximum displacement are $20-30^{\circ}$ of varus, $20^{\circ}$ of apex anterior angulation, $15^{\circ}$ of internal rotation and bayonet apposition with 1-2 cm of shortening. ${ }^{1}$ Rotational alignment is least remodelled. However, rotations are well compensated by the shoulder.
Conservative treatment options include coaptation splint immobilization, sling and swathe, functional bracing, hanging arm cast and traction. ${ }^{6,7}$ Traction is only of historical value nowadays. The hanging arm cast seems to have maximum stiffness of the elbow. Humeral shaft fractures are immobilized for 2-3 weeks with gentle exercises on coaptation splint removal. Coaptation splints tend to cause loss of reduction once the swelling subsides. ${ }^{3}$ Splints can be applied under analgesia, or under anaesthesia to relax the muscles. Sarmiento functional bracing gives good stability and also allows active elbow movements. ${ }^{8,9}$ Swelling precludes bracing initially and 2 weeks of splinting followed by bracing can be done.

Surgery is indicated for open fractures, soft tissue injuries, multiple injury patients, floating elbow injuries and unacceptable alignment following closed manipulation. ${ }^{1-6}$ Either, more commonly IM elastic nails or rarely a plate and screw construct are necessary. For extensive soft tissue injuries and open fractures, external fixation devices are indicated. Recently, for the early mobilization of shoulder and elbow and adequate anatomical reduction IM nails are being used for many isolated humeral shaft fractures. ${ }^{10}$

In our case, the spiral fracture of the humeral shaft was very much displaced with rotation of the proximal fragment. Acceptable limits of angulation were present. Manipulation under anaesthesia helped reduce the translation and rotation and to a certain extent the angulation. Healing was delayed due to coaptation slab loosening and hence was converted to a functional orthosis. The functional orthosis gave adequate stability and early mobilization of the joints to give excellent functional results. Further, reduction in angulation by $3-5^{\circ}$ both in sagittal and coronal planes is noted showing early signs of remodelling even at 3 months of follow-up.

\section{CONCLUSION}

Spiral humeral shaft fractures make up 50\% of all humeral shaft fractures in paediatric age group children. ${ }^{3}$ They are mostly treated conservatively and heal well. In our case, manipulation led to acceptable levels of angulation and no deformity visible clinically. Joints were supple with a good range of motion post treatment. Functional bracing provided adequate stability and early mobilization. Radial nerve was not injured. Our case demonstrates that isolated adolescent humeral spiral fractures can still be managed conservatively with excellent functional recovery.

\section{ACKNOWLEDGEMENTS}

We would like to acknowledge the patient for consenting for procedure and clinical pictures and Sri Ramachandra institute of higher education and research for allowing us to publish the study.

Funding: No funding sources

Conflict of interest: None declared

Ethical approval: Not required 


\section{REFERENCES}

1. Bae DS. Shoulder dislocation and fractures of the proximal humerus and humeral shaft, In: Waters PM, Skaggs DL, Flynn JM, eds. Rockwood and Wilkins Fractures in Children, Wolters Kluwer 9th edition, Philadelphia; 2019: 695-711.

2. Beaty JH. Fractures of the proximal humerus and shaft in children, Instr Course Lect. PMID 1588080. 1992;41:369-72.

3. Shaughnessy MAO, Parry JA, Liu H, Stans AA, Larson AN, Milbrandt TA. Management of paediatric humeral shaft fractures and associated nerve palsy. Journal of Children's Orthopaedics. 2019;13(5):508-15.

4. Caviglia H, Garrido CP, Palazzi FF. Pediatric Fractures of the Humerus. Clin Orthop and Related Res. 2005;432:49-56.

5. Skaggs DL, Frick S. Upper extremity fractures in children, In: Stuart LW, John MF, eds. Lovell and Winter's pediatric orthopaedics, Wolters Kluwer 7th edition, Philadelphia; 2014: 1702-1708.

6. Canavese F, Marengo L, Cravino M, Giacometti V, Pereira B, Dimeglio A, et al. Outcome of Conservative Versus Surgical Treatment of Humeral Shaft Fracture in Children and Adolescents:
Comparison Between Nonoperative Treatment (Desault's Bandage), External Fixation and Elastic Stable Intramedullary Nailing. J Pediatr Orthop. 2017;37(3):156-63.

7. Holm CL. Management of humeral shaft fractures. Fundamental nonoperative technics, Clin Orthop Relat Res. 1970;71:132-9.

8. Sarmiento A, Kinman PB, Galvin EG, Schmitt RH, Phillips JG. Functional bracing of fractures of the shaft of the humerus. J Bone Joint Surg Am. 1977;59(5):596-601.

9. Sharma VK, Jain AK, Gupta RK, Tyagi AK, Sethi PK. Non-operative treatment of fractures of the humeral shaft: a comparative study. J Indian Med Assoc. 1991;89(6):157-60.

10. Abosalim A, El-Din A, El-Mowafy H. Treatment of humeral shaft fractures by a single elastic stable intramedullary nail in children. Menoufia Med J. 2015;28(1):125-32.

Cite this article as: Thiyagarajan TS, Harshavardhan JKG. Coaptation and functional bracing of adolescent humeral shaft spiral fracture: a case report and review of literature. Int J Res Orthop 2020;6:628-31. 